$10-1-2020$

\title{
Trends in maternal health services in Bangladesh before, during and after COVID-19 lockdowns: Evidence from national routine service data
}

Sigma Ainul

Population Council

Md. Saddam Hossain

Population Council

Md. Irfan Hossain

Population Council

Md. Kamruzzaman Bhuiyan

Sharif M.I. Hossain

Population Council

See next page for additional authors

Follow this and additional works at: https://knowledgecommons.popcouncil.org/departments_sbsr-rh How does access to this work benefit you? Let us know!

\section{Recommended Citation}

Ainul, Sigma, Md. Saddam Hossain, Md. Irfan Hossain, Md. Kamruzzaman Bhuiyan, Sharif M.I. Hossain, Ubaidur Rob, and Ashish Bajracharya. 2020. "Trends in maternal health services in Bangladesh before, during and after COVID-19 lockdowns: Evidence from national routine service data," COVID-19 Research Brief. Dhaka: Population Council. 


\section{Authors}

Sigma Ainul, Md. Saddam Hossain, Md. Irfan Hossain, Md. Kamruzzaman Bhuiyan, Sharif M.I. Hossain, Ubaidur Rob, and Ashish Bajracharya 


\section{TRENDS IN MATERNAL HEALTH SERVICES IN BANGLADESH BEFORE, DURING AND AFTER COVID-19 LOCKDOWNS}

\section{Evidence from National Routine Service Data}

Maternal health service disruptions are clearly evident immediately following the COVID-19 pandemic lockdown in Bangladesh.

Short- and mid-term analyses of national and district data reveal:

- ANC and PNC services experienced immediate and severe declines at the onset of COVID-19 and lockdowns

- Both normal delivery and c-section in health care facilities faced considerable declines.

Most districts' maternal health services have begun recovery since the end of lockdown orders, but certain areas of Bangladesh continue service declines, indicating longer-term negative effects on maternal health services.

\section{Background}

Bangladesh instituted a national lockdown to contain community transmission of COVID-19, initially for 10 days, from March $26^{\text {th }}$ to April $4^{\text {th }}, 2020$, then extended successively through May $30^{\text {th }}$. During the lockdown, the pandemic and its mitigation measures' impacts on social, economic, and financial aspects of life in Bangladesh were widely documented. i,i ii $_{\text {ii }}$ Disruptions to the health system, particularly critical maternal health services, however, have received relatively less attention.

This study analyzed potential impacts of COVID-19 and its related mitigation measures on maternal health services in Bangladesh, examining national and district trends in antenatal care (ANC), institutional delivery, and postnatal care (PNC) by utilizing publicly available routine service statistics from before, during, and after the lockdown.

\section{Methods}

Routine monthly service statistics from January through July 2020 from the Directorate General of Family Planning (DGFP) of Bangladesh's Ministry of Health and Family Welfare (MoHFW) were examined to determine ANC, institutional delivery, and PNC service trends. Analysis did not include statistics from the Directorate General of Health Service (DGHS), which are not publicly available. Comparisons with data from the first seven months of 2019 are presented to account for seasonal trends.

\section{National Results}

ANC visits: ANC visits (ANC1, ANC 2, ANC 3, ANC4) began declines in March 2020, at the onset of COVID-19 in Bangladesh, with accelerated decline in April 2020 immediately following the national lockdown (see Figure 1).
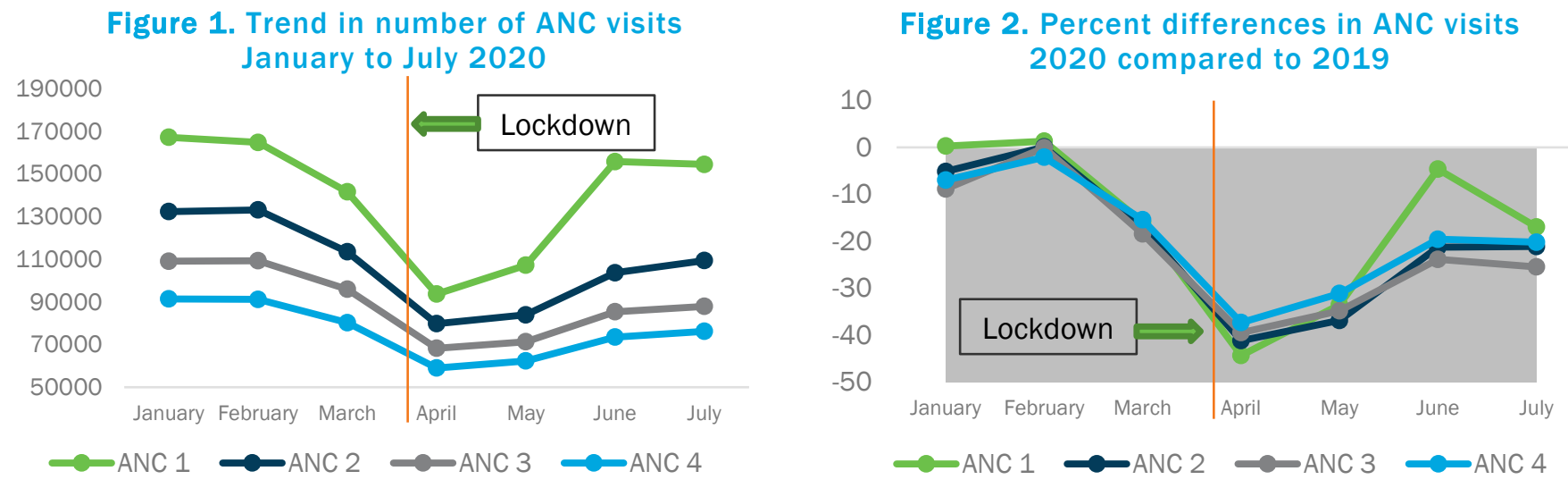

ANC visits began recovering between May and July 2020, especially for ANC1, but service figures are still far below figures observed for the same months in 2019 (Figure 2). 
Relative percentage differences in ANC visits in 2020 and 2019, comparing figures for the same months (Figure 2) indicate a clear disruption in ANC services at the onset of COVID-19 and the lockdown, specifically when comparing March through May for both years. ANC visits were 50\% lower in April 2020 compared to April 2019. Even after signs of recovery in June and July 2020, ANC figures remained $20 \%$ to $25 \%$ lower than in July 2019, particularly ANC2, ANC3, and ANC4.

PNC visits: A clear negative trend in PNC visits (PNC 1, PNC 2, PNC 3, PNC 4) occurred between March and April 2020 at the onset of the COVID-19 lockdowns in Bangladesh. Similar to ANC, PNC figures recovered slightly in May 2020 and steadily into June and July 2020, but not to pre-pandemic levels (Figure 3).
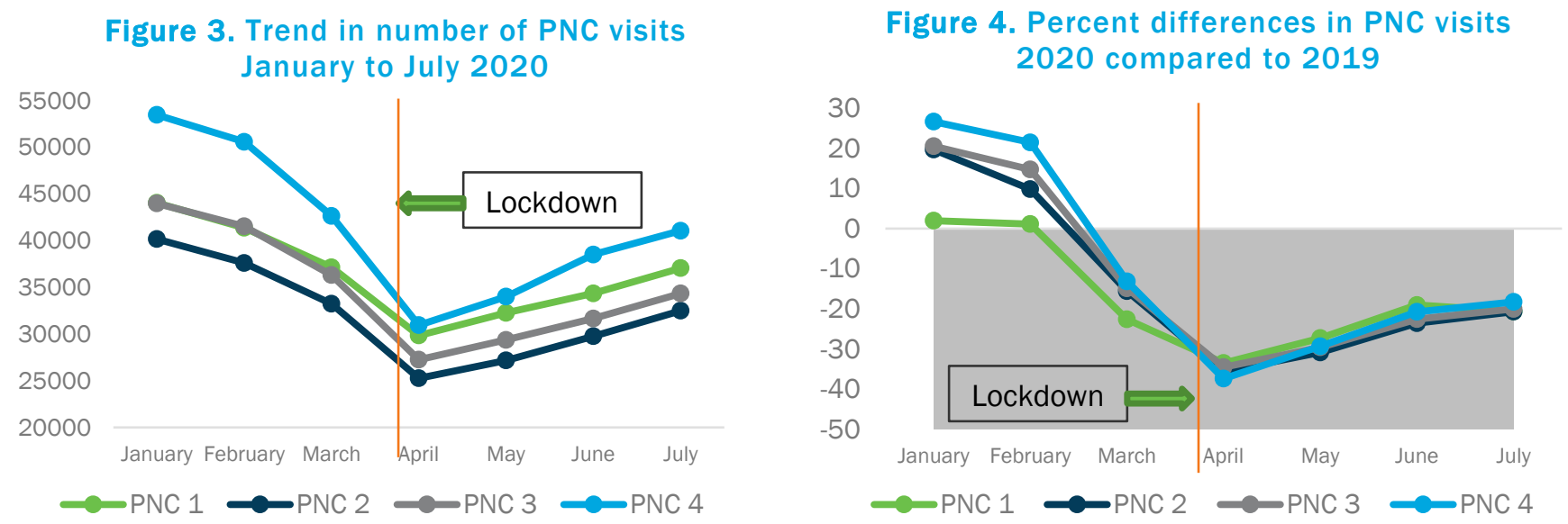

Relative monthly percentage differences in PNC visits in 2020 and 2019 (Figure 4) indicate clear service disruption from March through May 2020. PNC visits for all services were as much as $40 \%$ lower in April 2020 compared to April 2019. Even with recovery by June and July 2020, PNC figures remained $20 \%$ to $25 \%$ lower than they were in June and July 2019.

Institutional delivery: Institutional delivery declined relatively less abruptly in March and April 2020, with gradual recovery observed after April (Figure 5).

Figure 5. Trend of normal, c-section, AMTSL delivery, January 2020 to July 2020

\section{Figure 6. Percent differences in delivery 2020 compared to 2019}
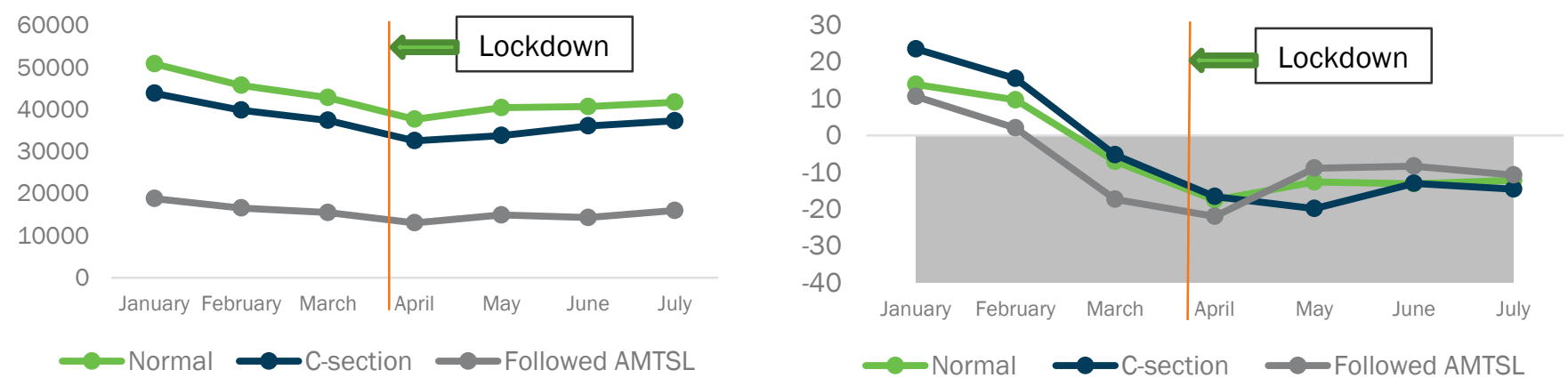

Relative percentage differences for the same periods in 2020 and 2019, by month, show substantial differences in all types of institutional delivery services-normal delivery, active management of third stage of labor (AMTSL), and c-section (Figure 6).

All forms of institutional delivery were $15 \%$ and $20 \%$ lower in April 2020, following the lockdown, compared to April 2019. Institutional delivery, despite its slight recovery, remained $10 \%$ to $20 \%$ lower in May, and then $10 \%$ to $15 \%$ lower in June and July 2020 than they were during the during the same months the previous year. 


\section{District Results}

\section{Changes between February and April 2020-and February 2020 compared to July 2020}

Trends in changes for ANC, PNC, and institutional delivery within individual districts were also examined to illustrate geographic trends in the country's maternal health service disruptions. To capture immediate trends at the onset of COVID-19 and its resultant lockdowns, service delivery for February 2020, immediately preceding COVID-19 and its lockdowns, was compared with April 2020, following the lockdowns. To assess longer-term trends, February 2020 service statistics were also compared with statistics from July 2020, after lockdowns had ceased. A series of district maps ( 1 a through $5 b$ ) illustrate the changes in trends for ANC, institutional delivery, and PNC during these two periods of time.

ANC visits: Between February and April 2020, when COVID-19 lockdowns were under enforcement, fully half (32 of 64 total) of Bangladesh's districts experienced immediate reductions in ANC1 services, as much as $40 \%$ (map 1a)-while declines as great as $60 \%$ in ANC1 occurred in 29 districts for the same period, mostly in neighboring Dhaka and Chattogram and far eastern districts in Sylhet division. Gazipur and Sherpur districts had the highest disruptions in ANC1 visits, $70 \%$ and $69 \%$, respectively, from February to April.

Although recovery was observed in most districts when data from February and July were compared (map 1b), Chattogram, Gazipur, Sherpur, Mymensigh, Tangail, Narshingdi, and Sunamganj continued significant ANC1 service disruption through July.

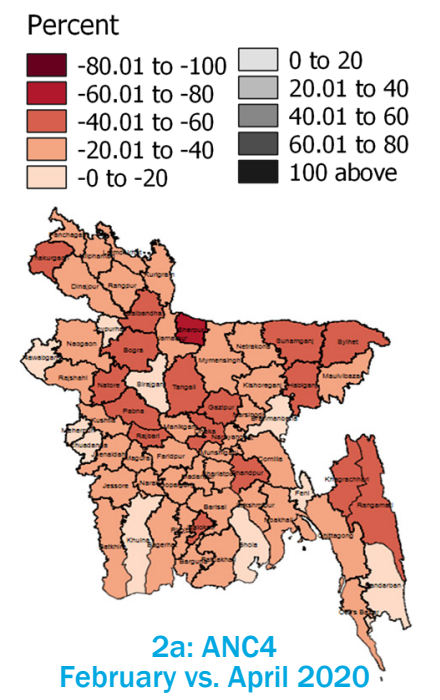

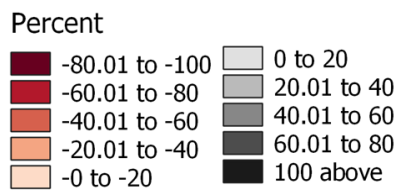

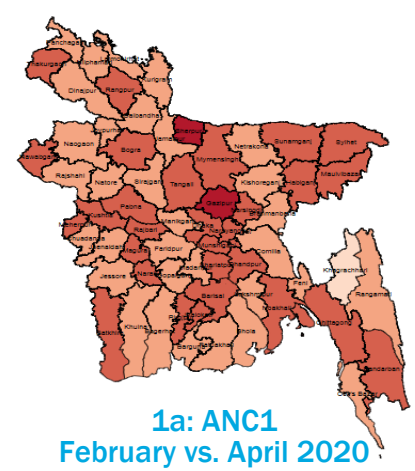

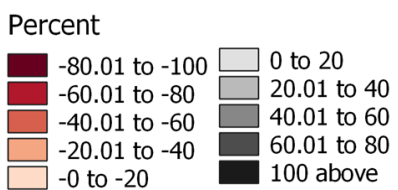

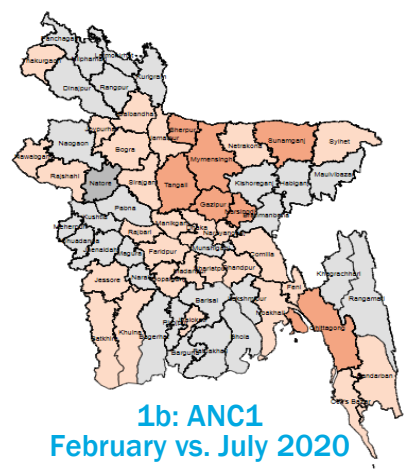

Services for ANC4 declined abruptly throughout the country in April, following the lockdown, with declines as great as $40 \%$ in nearly two thirds $(n=37)$ of districts, and even greater declines-as high as 60\% in another 16 districts (map 2a). Dhaka and its neighboring districts such as Rajbari and Chandpur, along with far eastern districts in Sylhet division and northern districts such as Thakurgaon and Gaibandha experienced the more significant disruptions, while the greatest disruption to ANC4 services occurred in Sherpur district: $71 \%$.

While the situation improved in a number of districts by July, ANC1 services improved much more than ANC4. Twenty-six districts continued disrupted ANC4 service (map 2b), with declines as great as 40\% through July, while Sherpur, Tangail, and Rajbari experienced declines higher than $40 \%$, and Thakurgaon had the greatest decline of all, $50 \%$, through July. 
PNC visits: PNC1 declined in April 2020, immediately after the lockdown, but not as severely as ANC services. PNC1 in 18 districts declined less than 20\%, while more than half $(n=34)$ of districts declined from $20 \%$ to 40\% (map 3a). Reductions in PNC1 services greater than $40 \%$ to $60 \%$ occurred in 12 districts, in Dhaka and three surrounding districts (Naranganj, Gazipur, Rajbari), four districts in north-central Bangladesh (Bogura, Joypurhat, Naogaon, Sherpur), and a few districts in the south. While a gradual recovery in PNC1 services has occurred in most districts, substantial service declines continued through July. One third of districts $(n=22)$ continued PNC1 declines as much as $40 \%$, while another still had declines of up to $20 \%$, when data from February and July were compared. Panchghar, Joypurhat, Tangail, and Feni districts' PNC1 service statistics were $40 \%$ to $60 \%$ lower in July despite the end of lockdown measures, which could indicate longer-term negative impacts of COVID-19 on PNC1.
Percent
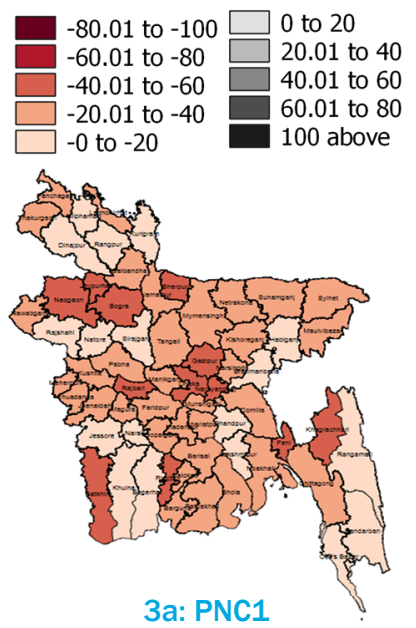

February vs. April 2020
Percent

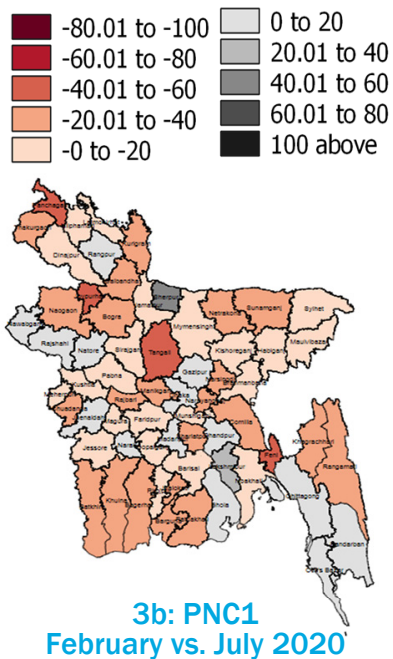

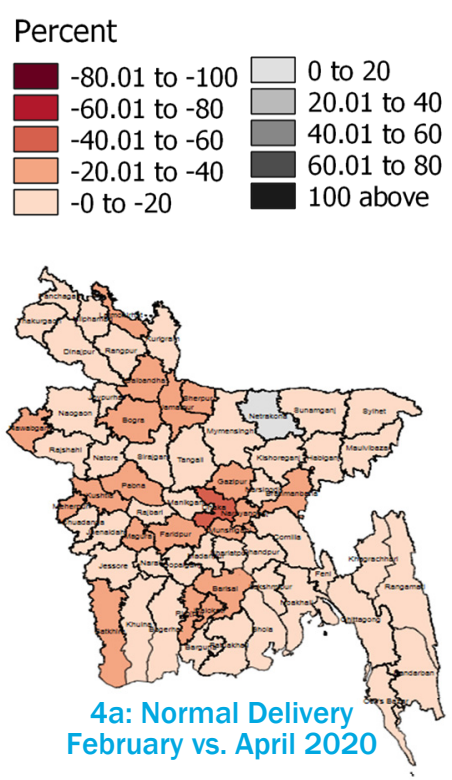
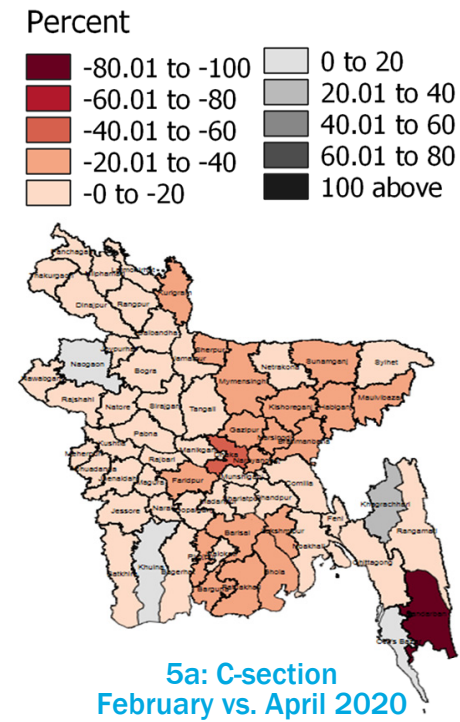

Percent
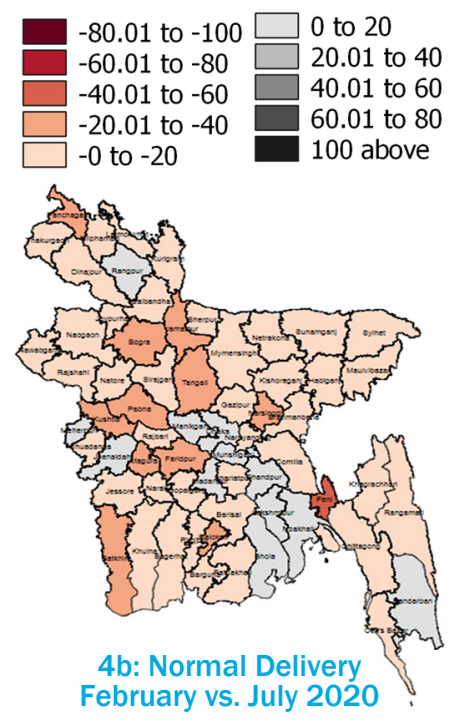

Percent
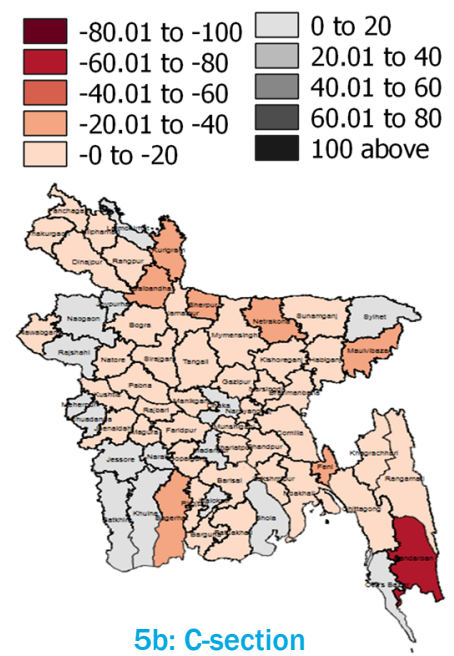

February vs. July 2020
Institutional delivery: Both normal deliveries and c-sections at health care facilities declined in April after the lockdown (maps $4 a$ and 5a). Substantial declines, as great as $20 \%$, were observed in most districts for both normal delivery (43 districts) and c-section (40 districts), while around one third of districts observed even higher declines, as large as $40 \%$, for normal delivery (19 districts) and c-section (18 districts).

Major disruptions in institutional delivery occurred in Dhaka for both normal delivery (42\%) and csection (41\%). After the lockdown ended, however, rapid recovery had occurred in Dhaka by July.

For most districts across the country, though, recovery has been slower, for both institutional normal delivery and c-section. Three fourths of districts still recorded declines (maps $4 \mathrm{~b}$ and $5 \mathrm{~b}$ ) in services of up to $20 \%$ through July 2020. 


\section{Discussion and Conclusions}

Clear disruptions in maternal health services following COVID-19 and its resultant lockdowns are evident in both shortand mid-term analyses of Bangladesh's district statistics. ANC and PNC visits were apparently more immediately affected by implementation of national lockdowns. Both institutional normal deliveries and c-sections declined substantially across the country. With the end of lockdowns, slow recovery and gradual reversal in negative maternal health service trends-for ANC, PNC, and institutional delivery-occurred throughout the country in July 2020. Although general trends are encouraging, many districts continue relative declines in service, and certain districts show no recovery, possibly indicative of longer-term negative impacts on maternal health care in certain parts of Bangladesh.

COVID-19 related disruptions may be related to:

- Restricted mobility of clients as well as service providers due to lockdowns

- Fear among pregnant women and communities of COVID-19 infection at health care facilities

- Financial barriers to seeking services due to economic and financial insecurity resulting from COVID-19

- Lack of safety equipment and mitigation measures at facilities that prevented safe provision of regular services

- Challenges to coordination between service providers and authorities for continuation of regular services during the pandemic, and challenges for service preparedness including referrals and patient management, and

- Fear, stigma, and negative attitudes due to COVID-19 within communities towards their service providers

\section{Recommendations}

Both the immediate and potential long-term disruptions in ANC, PNC, and institutional delivery in Bangladesh could result in preventable maternal, newborn and child mortality and morbidity. For maternal health services to return to normal levels prior to the pandemic, specific measures should be implemented:

- Develop targeted interventions that rebuild trust between communities and the health system, especially frontline health care providers, amid fears and stigma related to COVID-19.

- Monitor and routinely analyze facility service statistics to support MoHFW's identification of low-performing and slowly recovering districts, where targeted actions can help restore levels of service.

- Develop standard operating procedures (SOPs) for maternal health service continuation during COVID-19, and preparedness plans for potential future emergencies-including similar pandemic scenarios or potential future waves of COVID-19; such plans should include clear instructions for community outreach in addition to facility and health worker readiness, considering all appropriate safety measures.

- Incentivize health care providers' continued services during the pandemic while ensuring service providers and facilities have appropriate safety equipment and measures such as PPE and logistics plans for emergency settings to improve provider confidence in their own health and safety.

- Dedicated research, such as structured surveys and in-depth interviews with pregnant mothers and service providers, is needed to assess both supply and demand factors, and understand the barriers to maternal health services during COVID-19, with particular attention to pregnant women's fears and anxieties about visiting facilities, in addition to the stigma and mistreatment of frontline health workers, to ensure evidence-based adaptation of services.

Partnering with national health ministries and other government agencies in sub-Saharan Africa, South Asia, and Latin America, Population Council global and in-country scientists are conducting COVID-19 public health and social science research to produce relevant and timely evidence to support policymakers in controlling the spread of coronavirus, evaluating the effectiveness of prevention and mitigation measures, and assessing longer-term health, social and economic effects of the pandemic.

SUGGESTED CITATION: Sigma Ainul, Md. Saddam Hossain, Md. Irfan Hossain, Md. Kamruzzaman Bhuiyan, Sharif M. I. Hossain, Ubaidur Rob, Ashish Bajracharya. Trends in Maternal Health Services in Bangladesh Before, During and After COVID-19 Lockdowns: Evidence from National Routine Service Data. Research Brief. Dhaka: Population Council. September 2020.

(C2020 The Population Council, Inc.

PPRC \& BIGD, May 2020. PPRC-BIGD rapid response research. Livelihoods, coping and support during COVID-19 crisis. https://bigd.bracu.ac.bd/wpcontent/uploads/2020/05/PPRC-BIGD-Final-April-Survey-Report.pdf

ii Hamadani et al. 2020. Immediate impact of stay-at-home orders to control COVID-19 transmission on socioeconomic conditions, food insecurity, mental health, and intimate partner violence in Bangladeshi women and their families: an interrupted time series. The Lancet Global Health

iii Population Council. 2020. Bangladesh: COVID-19 Knowledge, Attitudes, Practices \& Needs: Responses from the first round of data collection among adolescent girls in five districts. 